\title{
6

\section{Confirming Whether Fine Needle Biopsy Device Shortens the Learning Curve of Endoscopic Ultrasound-Guided Tissue Acquisition Without Rapid Onsite Evaluation}

\author{
Meng-Ying Lin ${ }^{1}$, Cheng-Lin Wu', Mitsuhiro Kida ${ }^{3}$, Wei-Lun Chang ${ }^{1}$ and Bor-Shyang Sheu ${ }^{1,4}$ \\ ${ }^{1}$ Department of Internal Medicine, National Cheng Kung University Hospital, Tainan, ${ }^{2}$ Department of pathology, National Cheng Kung \\ University Hospital, Tainan, Taiwan ${ }^{3}$ Department of Gastroenterology, Kitasato University School of Medicine, Kanagawa, Japan, \\ ${ }^{4}$ Institute of Clinical Medicine, College of Medicine, Kaohsiung Medical University, Kaohsiung, Taiwan
}

Background/Aims: Endoscopic ultrasonography (EUS)-guided tissue acquisition requires a long learning curve. We aimed to compare the skill maturation curves between fine needle aspiration (FNA) and biopsy (FNB) for tissue acquisition.

Methods: The initial 60 procedures performed by the trainee endosonographer (30 FNA vs. $30 \mathrm{FNB}$ ) were consecutively enrolled. The difference in procedure performance was compared between the two groups. Learning curves were assessed. Twenty additional cases were subsequently enrolled to assess the consistency of performance in the FNB group.

Results: The FNB group acquired larger tissue samples $\left(2.35 v s .0 .70 \mathrm{~mm}^{2} ; p<0.001\right)$ with lower blood content $(p=0.001)$ and higher tissue quality $(p=0.017)$ compared with the FNA group. In addition, the FNB group required less needle pass to establish a diagnosis ( 2.43 vs. 2.97; $p=0.006$ ). A threshold diagnostic sensitivity of $\geq 80 \%$ was achieved after performing 10 FNB procedures. The number of needle passes significantly decreased after conducting $20 \mathrm{FNB}$ procedures $(1.80 \mathrm{vs.} 2.70 ; p=0.041)$. The diagnostic sensitivity and number of needle passes remained the same in the subsequent FNB procedures. By contrast, this skill maturation phenomenon was not observed after performing 30 FNA procedures.

Conclusions: In EUS-guided tissue acquisition, the FNB needle was more efficient and thus shortened the learning curve of EUSguided tissue acquisition in trainee endosonographers. Clin Endosc 2021;54:420-427

Key Words: Core needle biopsy; Endoscopic ultrasonography; Fine needle aspiration; Gastrointestinal endoscopes; Programmed learning

\section{INTRODUCTION}

Endoscopic ultrasonography (EUS)-guided tissue acquisition (TA) has evolved as an important tool for diagnosing gastrointestinal tract subepithelial mass lesion and pancreatobili- ary disease since the first report of EUS fine needle aspiration (FNA) by Vilmann et al. in 1992. ${ }^{1}$ Because of its high sensitivity, specificity, accuracy, and relatively lower complication rate, EUS TA had gradually replaced the percutaneous and surgical TA in this field, and has become the standard procedure in

\footnotetext{
Received: July 10, 2020 Revised: December 1, 2020

Accepted: December 1, 2020

Correspondence: Wei-Lun Chang

Department of Internal Medicine, National Cheng Kung University Hospital, No.138, Sheng Li Road, Tainan 704, Taiwan

Tel: +886-6-235-3535 ext. 5368, Fax: +886-6-2766175, E-mail: weilun1@mail.ncku.edu.tw

ORCID: https://orcid.org/0000-0002-0238-527X

Bor-Shyang Sheu

Department of Internal Medicine, National Cheng Kung University Hospital, No.138, Sheng Li Road, Tainan 704 and Institute of Clinical Medicine, College of Medicine, Kaohsiung Medical University, No.100, Shin-Chuan 1st Road, Sanmin Dist, Kaohsiung 807, Taiwan

Tel: +886-6-2353535 ext. 5368, Fax: +886-6-2766175, E-mail: sheubs@mail.ncku.edu.tw

ORCID: https://orcid.org/0000-0002-1500-6929
}

(c) This is an Open Access article distributed under the terms of the Creative Commons Attribution Non-Commercial License (http://creativecommons.org/licenses/by$\mathrm{nc} / 3.0$ ) which permits unrestricted non-commercial use, distribution, and reproduction in any medium, provided the original work is properly cited. 
many medical centers. ${ }^{2-4}$

According to the targeted lesion, 5-7 needle passes were recommended in order to obtain adequate tissue samples to achieve cytopathological diagnosis through EUS FNA. ${ }^{5}$ After the introduction of rapid on-site evaluation (ROSE), the needle pass number had decreased to $3.4 \pm 2.2$ times. $^{6}$ However, only limited hospitals have on-site cytopathologists during EUS FNA, thus making it difficult to implement ROSE worldwide. $^{7}$ Additionally, EUS exam and EUS FNA are operator-dependent procedures, and their efficacy relied heavily on the operator's experiences with a long learning curve. ${ }^{8,9}$ Previous studies on EUS FNA learning curve showed that 20-30 cases were required to increase the diagnostic sensitivity to a globally acceptable threshold of $80 \%$, and 150 cases were needed to decrease the needle pass number while maintaining tissue adequacy. ${ }^{10,11}$ Recent advances in neoadjuvant chemotherapy for borderline operable pancreatic cancer further increased the demand for this procedure for histological confirmation. ${ }^{12,13}$ Therefore, improving the effectiveness and efficiency of EUS TA has become an important issue recently.

To improve the quality of the obtained tissue sample, an EUS fine needle biopsy (FNB) needle was developed and marketed recently. Its special needle tip allows the operator to obtain a core tissue sample with preserved architecture, which can greatly improve the diagnosis ability. Several recent studies revealed that EUS TA with FNB needle had a diagnostic performance comparable to that of EUS TA with FNA needle while increasing the acquired tissue size and improving histological quality. In the hands of a proficient operator, the FNB needle more efficiently obtained core tissue samples and required fewer needle passes. ${ }^{14-16}$ However, all current studies were carried out by expert endoscopists. Whether this novel needle device could shorten the learning curve in trainee endosonographers still needs to be investigated further.

\section{MATERIALS AND METHODS}

\section{Patients and study design}

This retrospective study consecutively enrolled the first 60 patients who underwent EUS TA (30 FNA vs. $30 \mathrm{FNB}$ ) at a tertiary center in southern Taiwan between September 2016 and August 2019. Written informed consent was obtained from all patients. The study was approved by the National Cheng Kung University Hospital Institutional Review Board (B-BR-108-070). The EUS TA procedures were performed by two endosonographers who were experienced in conducting diagnostic EUS examinations ( $>150$ cases, including $>75$ pancreatobiliary cases 2 years prior to this study), and at least 30
EUS TA procedures were performed by experts in a center that conducts a high volume of EUS procedures (Mitsuhiro Kida, $\mathrm{MD}, \mathrm{PhD}$ and Hiroshi Imaizumi, $\mathrm{MD}, \mathrm{PhD}$, Kitasato University Hospital, Kanagawa, Japan). According to American Society for Gastrointestinal Endoscopy and the British Society of Gastroenterology, endosonographers need to perform 50 EUS TA procedures (25 pancreatic cases and 25 others) to achieve skill maturation. The two endoscopists who performed the EUS TA procedures in this study were trainee endosonographers. ${ }^{8,17}$ The technical success and number of needle passes required to establish a diagnosis, tissue area and amount of blood during the histological assessment, adequacy of obtained tissue, and complications were recorded. In addition, the malignancy diagnostic sensitivity, specificity, and overall diagnostic accuracy were analyzed and compared between the two groups. The learning curves of EUS TA using different needle types were analyzed by chronologic subgroups, with each group comprising 10 procedures. Another $20 \mathrm{FNB}$ procedures after initial enrollment were included to prove the stability of performance after skill maturation.

\section{EUS tissue acquisition}

The EUS TA procedure was performed under analgesia with or without conscious sedation. The needle size and suction method were determined according to the literature's recommendation and endosonographers' preference. ${ }^{18}$ We used EZ shot 2 (19 G, 22 G, and 25 G; Olympus Medical Systems, Tokyo, Japan), EchoTip Ultra (22 G; Cook endoscopy Inc., Bloomington, IN, USA), and Expect ${ }^{\mathrm{TM}}$ (22 G; Boston scientific Corp., Natick, MA, USA) in the FNA group. EchoTip ProCore (19 G and $20 \mathrm{G}$; Cook endoscopy Inc., Bloomington, IN, USA) and Acquire ${ }^{\mathrm{TM}}$ (22 G; Boston Scientific Corp., Natick, MA, USA) were applied in the FNB group. Details regarding the types of needles used and chronological order of the procedure are listed in Table 1. The EUS TA procedure was discontinued when more than 4-mm whitish core tissue was collected based on macroscopic on-site evaluation (MOSE). ${ }^{19-}$

${ }^{22}$ Recent studies on MOSE showed that a 4-mm whitish core tissue achieved a diagnostic sensitivity of $92.4 \%-94.3 \%$ using 19-G, 20-G, and 22-G FNA/FNB needles. All procedures were conducted under a linear scanning ultrasound scope (GFUCT260; Olympus, Tokyo, Japan) using either the EU-ME1 or EU-ME2 system. After puncture, a stylet, a 10-ml syringe filled with saline, and a 10-ml syringe filled with air were sequentially used to push the tissue out of the biopsy needle onto a sterile plate, and the adequacy of core tissue was evaluated MOSE. After MOSE, the obtained tissues were fixed with formalin and sent to the pathology department for histological assessment. 
Table 1. Needle Selection in Both Groups

\begin{tabular}{|c|c|c|c|}
\hline & FNA group $(n=30)$ & FNB group $(n=30)$ & $p$ value \\
\hline Needle size $\left(\mathrm{O}^{\mathrm{a})} / \mathrm{C}^{\mathrm{b}} / \mathrm{B}^{\mathrm{c})}\right)$ & & & $<0.001^{\mathrm{d})}$ \\
\hline $19 \mathrm{G}$ & $7(1 / 0 / 0)$ & $1(0 / 1 / 0)$ & \\
\hline $20 \mathrm{G}$ & 0 & $23(0 / 23 / 0)$ & \\
\hline $22 \mathrm{G}$ & $21(11 / 7 / 3)$ & $6(0 / 0 / 6)$ & \\
\hline $25 \mathrm{G}$ & $2(2 / 0 / 0)$ & 0 & \\
\hline The time order of procedure & & & $<0.001$ \\
\hline $1-10$ & 8 & 2 & \\
\hline $11-20$ & 10 & 0 & \\
\hline $21-30$ & 7 & 3 & \\
\hline $31-40$ & 3 & 7 & \\
\hline $41-50$ & 0 & 10 & \\
\hline $51-60$ & 2 & 8 & \\
\hline
\end{tabular}

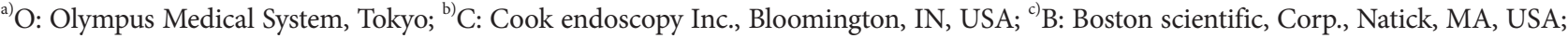

${ }^{\mathrm{d})}$ Comparing the difference in needle size, not company.
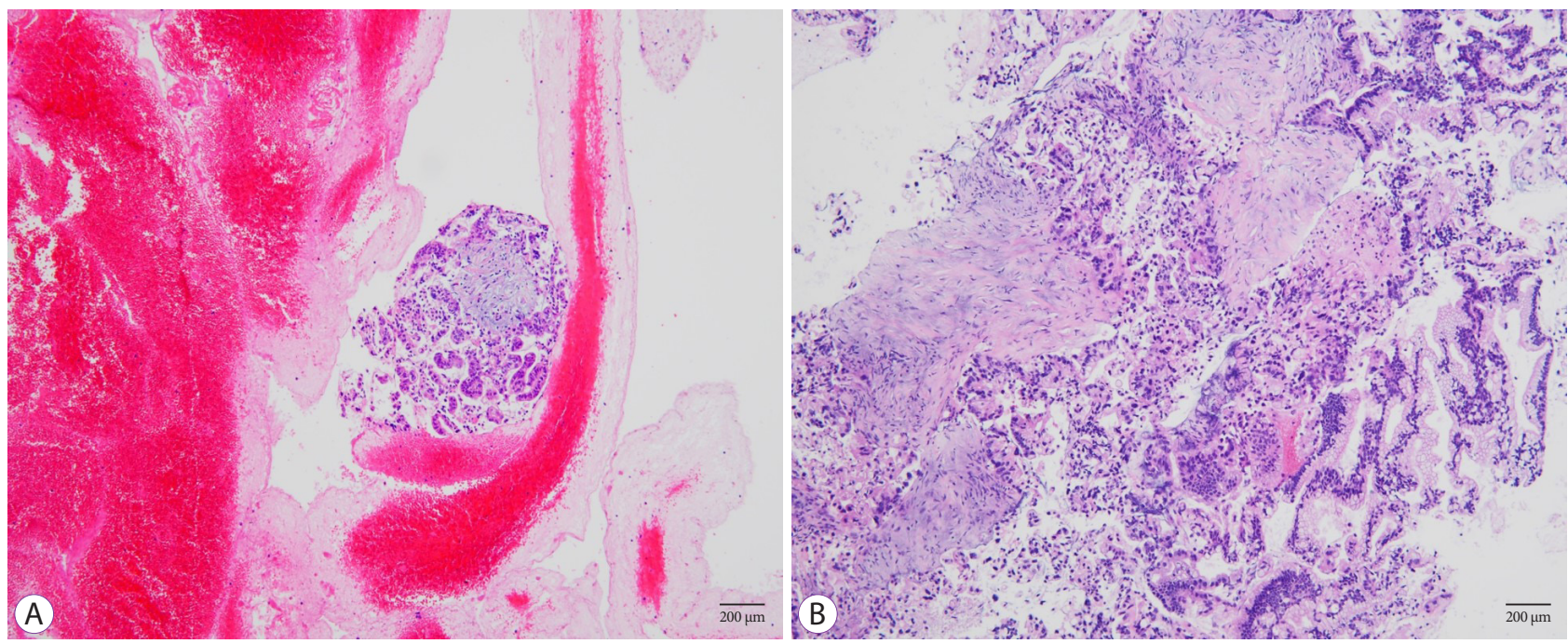

Fig. 1. Images of histological samples acquired using different types of needles (H\&E stain, 100X). (A) Tissue samples acquired using an fine needle aspiration (FNA) needle contained large amounts of red blood cells with a small amount of tumor cells. (B) Tissue samples acquired using fine needle biopsy (FNB) needle contained tumor cells with a small amount of red blood cells.

\section{Tissue specimen handling and histological assessment}

At our institution, the formalin-fixed tissue specimens were routinely processed and embedded in paraffin in a histological tissue specimen handling room. The paraffin-embedded tissues were cut into $3-\mu \mathrm{m}$ slices. Only sections that mostly contained tissue specimens were processed into slides. The tissue sections were stained with hematoxylin and eosin for evaluation. Immunohistochemical procedures were performed when necessary. One gastrointestinal pathologist, who had no information regarding the patient's clinical condition and procedure details, was assigned to perform the histological assessment. The tissue area, blood clot contamination, and tissue adequacy for diagnosis were reported by the pathologist. The tissue area was determined based on the surface area of the specimen in a $3 \times 3$ square area under a $400 \times$ microscopic field (with each square measuring $0.24 \mathrm{~mm}^{2}$ ). Blood contaminants were evaluated using a 4-scale scoring method (Fig. 1). Tissue adequacy was confirmed by another pathologist in our hospital. 


\section{Data recording}

Patients' baseline characteristics including age, sex, indication for EUS TA, lesion size, and location were obtained from the electronic medical records of the National Cheng Kung University Hospital. During EUS TA, the total number of needle passes and procedure complications were indicated in the endoscopic report and obtained from the reporting system. Procedure success was defined as obtaining a sufficient amount of tissue for histologic diagnosis during EUS TA. All patients were followed for at least 3 months after the initial EUS TA to confirm the final diagnosis.

\section{Diagnostic interpretation}

The specimen was considered adequate if its structure is consistent with that of the tissues from the target organ and if it can be used to make a definitive diagnosis. The final diagnosis was confirmed based on either the result of EUS TA, histologic diagnosis using computed tomography-guided biopsy or surgical specimen, or the results of follow-up radiologic examination. The EUS TA result that met the final diagnosis was considered accurate. Cases with a final diagnosis of malignant disease were included for evaluation of sensitivity and specificity.

\section{Statistical analysis}

All statistical analyses were performed using SPSS software (version 20.0; IBM Corporation, Armonk, NY, USA). The differences in baseline characteristics, indications, and tumor locations were analyzed using Student's t-test or $\chi^{2}$ test, as appropriate. The sensitivity for malignant disease and accuracy of final diagnosis were calculated using a $2 \times 2$ table, and the performance between different needle devices was compared using the $\chi^{2}$ test. The histological adequacy was also compared using the $\chi^{2}$ test. The number of needle passes needed to establish a diagnosis and the average tissue area was assessed using the Student's t-test. After comparing the two groups, the diagnostic sensitivity and needle pass number were compared between subgroups of 10 procedures in chronological order using the $\chi^{2}$ test, while those within the same group were compared using the Student's t-test.

\section{RESULTS}

\section{Baseline characteristics of patients and features of target masses}

A total of 60 patients were included, including 30 patients who underwent EUS FNA and another 30 who underwent

Table 2. Baseline Characteristics of Enrolled Patients

\begin{tabular}{|c|c|c|c|}
\hline & FNA group $(n=30)$ & FNB group $(n=30)$ & $p$ value \\
\hline Age $($ mean $\pm \mathrm{SD})$ & $60.2 \pm 11.6$ & $62.5 \pm 13.8$ & 0.427 \\
\hline Gender (female: male) & $8: 22$ & 12: 18 & 0.273 \\
\hline $\begin{array}{l}\text { Mass location } \\
\text { Pancreatic UP and head } \\
\text { Pancreatic body and tail } \\
\text { Gastric SEML } \\
\text { Esophagus SEML } \\
\text { Others }^{\text {a) }}\end{array}$ & $\begin{array}{c}11 \\
13 \\
3 \\
0 \\
3\end{array}$ & $\begin{array}{c}14 \\
12 \\
0 \\
2 \\
2\end{array}$ & 0.231 \\
\hline $\begin{array}{l}\text { Mass size } \\
<1 \mathrm{~cm} \\
1-2 \mathrm{~cm} \\
>2 \mathrm{~cm}\end{array}$ & $\begin{array}{c}1 \\
8 \\
21\end{array}$ & $\begin{array}{c}1 \\
5 \\
24\end{array}$ & 0.640 \\
\hline $\begin{array}{l}\text { Final diagnosis } \\
\text { Pancreatic adenocarcinoma } \\
\text { Pancreatic NET } \\
\text { Pancreatic benign lesion } \\
\text { GIST } \\
\text { Leiomyoma } \\
\text { Other malignancy } \\
\text { Other benign }\end{array}$ & $\begin{array}{c}11 \\
4 \\
9 \\
1 \\
1 \\
4 \\
0\end{array}$ & $\begin{array}{c}13 \\
5 \\
4 \\
0 \\
2 \\
5 \\
1\end{array}$ & 0.590 \\
\hline
\end{tabular}

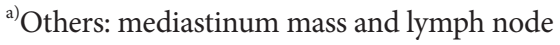

FNA, fine needle aspiration; FNB, fine needle biopsy; GIST, Gastrointestinal stromal tumor; NET, Neuroendocrine tumor; SD, standard deviation; SEML, Subepithelial mass lesion; UP, Uncinate process. 
EUS FNB. The characteristics of the enrolled patients are listed in Table 2. No significant difference was observed in the baseline characteristics between the two groups, including patients' age, sex, target mass location, and size. The final diagnosis of the target masses was also comparable between the groups.

\section{Difference of the diagnostic performance between FNB and FNA}

Both groups achieved a 100\% technical success rate. In Table 3 , the number of needle passes needed to establish a diagnosis was significantly lower in the FNB group than in the FNA group ( $2.43 \pm 0.90$ vs. $2.97 \pm 0.49 ; p=0.006)$. The FNB group obtained a significantly larger tissue sample $\left(2.35 \pm 1.75 \mathrm{~mm}^{2}\right.$ vs. $\left.0.70 \pm 1.04 \mathrm{~mm}^{2} ; p<0.001\right)$, had less blood contamination $(p=0.001)$, and had higher histology-adequacy ratio $(76.7 \%$ vs. $46.7 \%$; $p=0.017$ ) compared with the FNA group. The diagnostic sensitivity for malignant disease was higher in the FNB group, although the difference was not statistically significant (87.5\% vs. 60\%; $p=0.078$ ). The FNA results was not considered diagnostic due to the presence of atypical cells without stromal invasion, which occurred in 5 cases in the FNA group but none in the FNB group (Table 4). Only one complication (minor bleeding) was noted in the FNA group and resolved after appropriate medical treatment was provided.

\section{Learning curve evaluation}

In the FNB group, the diagnostic sensitivity for malignant disease increased gradually from the first to the third 10 cases

Table 3. Comparison of Diagnostic Performance Between the FNA Group and FNB Group

\begin{tabular}{|c|c|c|c|}
\hline & FNA group $(n=30)$ & FNB group $(n=30)$ & $p$ value \\
\hline \multicolumn{4}{|l|}{ Number of needle passes } \\
\hline Mean \pm SD & $2.97 \pm 0.49$ & $2.43 \pm 0.90$ & 0.006 \\
\hline 1 pass & 0 & 5 & 0.013 \\
\hline 2 passes & 4 & 9 & \\
\hline 3 passes & 23 & 15 & \\
\hline 4 passes & 3 & 0 & \\
\hline 5 passes & 0 & 1 & \\
\hline Tissue area $\left(\right.$ mean $\left.\pm \mathrm{SD}, \mathrm{mm}^{2}\right)$ & $0.70 \pm 1.04$ & $2.35 \pm 1.75$ & $<0.001$ \\
\hline Blood contains & & & 0.001 \\
\hline$<25 \%$ & 1 & 6 & \\
\hline $25 \%-50 \%$ & 2 & 9 & \\
\hline $50 \%-75 \%$ & 7 & 9 & \\
\hline$>75 \%$ & 20 & 6 & \\
\hline \multicolumn{4}{|l|}{ Histology quality } \\
\hline Acceptable & $14 / 30(46.7 \%)$ & $23 / 30(76.7 \%)$ & 0.017 \\
\hline Inacceptable & $16 / 30(53.3 \%)$ & $7 / 30(23.3 \%)$ & \\
\hline \multicolumn{4}{|l|}{ Histology } \\
\hline Sensitivity (malignancy) & $12 / 20(60 \%)$ & $21 / 24(87.5 \%)$ & 0.078 \\
\hline Specificity (malignancy) & $10 / 10(100 \%)$ & $6 / 6(100 \%)$ & 0.382 \\
\hline Accuracy (overall) & $20 / 30(66.7 \%)$ & $26 / 30(86.7 \%)$ & 0.125 \\
\hline Adverse effect & 1 & 0 & 0.491 \\
\hline
\end{tabular}

FNA, fine needle aspiration; FNB, fine needle biopsy; SD, standard deviation.

Table 4. Reasons for Undiagnostic Procedure

\begin{tabular}{lcc}
\hline & FNA group & FNB group \\
\hline Total undiagnostic procedure & 10 & 4 \\
Atypical cell without stromal invasion & 5 & 0 \\
Scant of cell & 2 & 1 \\
IHC stain negative & 1 & 1 \\
Blood clot & 1 & 1 \\
Sampling error & 1 & 1 \\
\hline
\end{tabular}

FNA, fine needle aspiration; FNB, fine needle biopsy. 


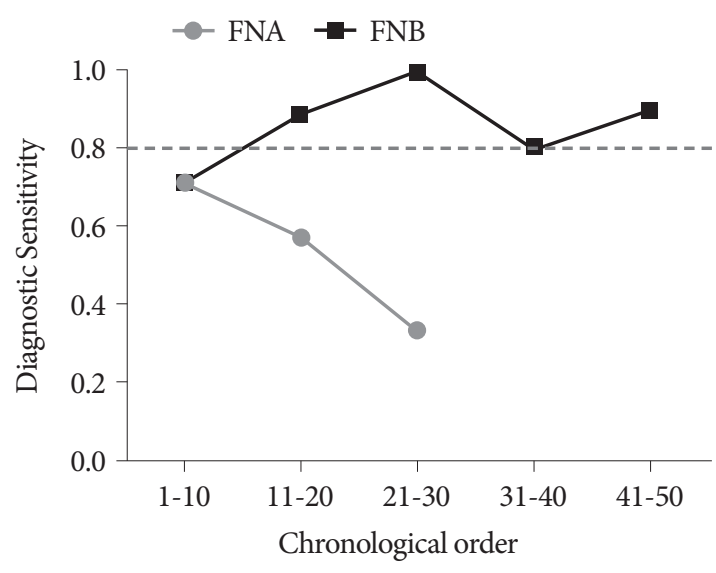

Fig. 2. Evolutional change of the diagnostic sensitivity for malignant disease in chronological order with FNA and FNB needles. The dotted line represents the globally acceptable diagnostic sensitivity threshold of $80 \%$. FNA, fine needle aspiration; FNB, fine needle biopsy.

(from $71.4 \%$ to $87.5 \%$ to $100 \%$ ). After 10 cases, the diagnostic sensitivity reached a satisfactory threshold $(>80 \%)$ and remained stable in the following cases even without an on-site cytopathologist to perform a ROSE. By contrast, the diagnostic sensitivity in the FNA group remained unsatisfactory within 30 procedures (Fig. 2). Moreover, the number of needle passes in 21-30 cases was significantly reduced compared with that in $1-10$ cases in the FNB groups $(2.10 \pm 0.316 v s .2 .70 \pm 0.675$; $p=0.020$ ), and remained stable in $31-50$ cases ( $p=0.643$ compared with that in 21-30 cases). However, this trend was not observed in the FNA group (Fig. 3).

\section{DISCUSSION}

EUS TA has largely replaced percutaneous TA in recent years because of its comparable accuracy but lower complication and needle-tract seeding rates. ${ }^{3,423}$ The changing trend in managing borderline resectable pancreatic cancer further increases the demand for this procedure. ${ }^{12,13}$ Therefore, improving the efficacy and efficiency of EUS TA is an important issue. Endosonographers can improve their performance in EUS TA by undergoing intensive training, but taking an intensive training on needle aspiration is time consuming. ${ }^{24,25}$ EUS biopsy needles have been developed recently, which can be used to acquire sufficient tissue samples with fewer needle passes if the operator is experienced. ${ }^{14,15,26}$ However, whether trainee endosonographers could benefit from these new devices during the training process remains unknown.

We found that the learning curve of trainee endosonogra-

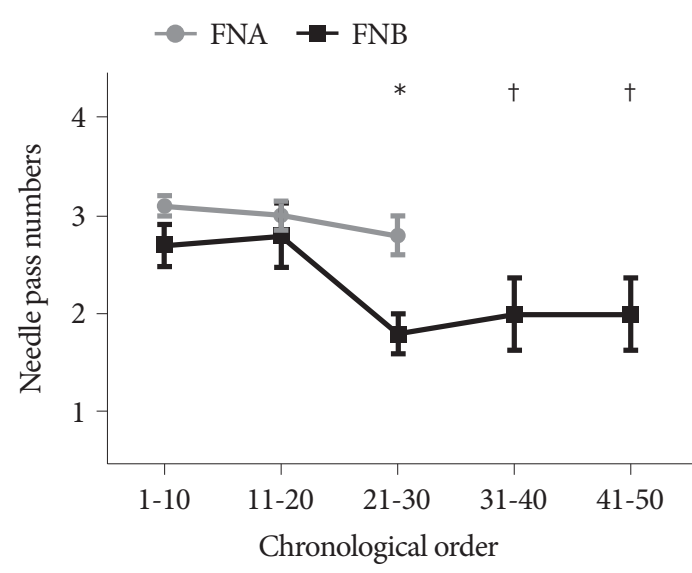

Fig. 3. Comparison of needle pass number in chronological order between endoscopic ultrasound (EUS) FNA and EUS FNB. FNA group did not show a significant reduction in needle pass number with the increasing number of procedures. In the FNB group, the number of needle passes required in 21-30 procedures was significantly lesser than that in $1-10$ or $11-20$ procedures $(*)$. In the validation step, the number of needle passes in 31-50 procedures was comparable to that in $21-30$ procedures in the FNB group $(\dagger)$. Data were presented as mean $\pm \mathrm{SE}$. EUS, endoscopic ultrasound; FNA, fine needle aspiration; FNB, fine needle biopsy; SE, Standard Error.

phers can be shortened when the FNB needle is used. To the best of our knowledge, we are the first to report this finding. In our study, a total of 10 procedures were required to achieve high diagnostic sensitivity for malignant disease ( $>80 \%$ ) using FNB needle without performing ROSE, which was lower than the reported 20-30 cases when using FNA needles with ROSE. ${ }^{10,11}$ Moreover, only 20 procedures were needed to decrease needle pass using FNB needles, which was far less than the 150 procedures performed in previous studies using FNA needles. ${ }^{10,11}$ Based on our study, the skills of trainee endosonographers in performing EUS TA procedures can quickly improve using the new FNB needle even without ROSE.

The advantages of FNB needle may help improve the trainee endosonographers skills in performing EUS TA. First, the special needle tip design of FNB can acquire larger tissue samples at a single try. ${ }^{27-29}$ Second, the FNB needle can obtain tissues with better preserved architecture or higher specimen adequacy. ${ }^{27,28,30}$ Third, FNB requires fewer needle passes to obtain sufficient specimen for diagnosis. ${ }^{27,29-31}$ Fourth, the specimens acquired by FNB contained less blood than that by FNA. Therefore, the better tissue acquisition ability and the acquired tissue quality of FNB devices may partially overcome the technical shortage of trainee endosonographers and allow them to achieve a globally acceptable diagnostic performance faster.

However, this study had some limitations. First, several needle sizes were used; nevertheless, previous studies had shown 
comparable diagnostic accuracy between 19-G, 22-G, and 25-G FNA needles, ${ }^{31-34}$ suggesting that needle size is not a major determinant of the diagnostic accuracy of FNA. The improved diagnostic performance of FNB observed in our study was mainly attributed to the needle design. We also performed a subgroup analysis comparing $19-\mathrm{G}$ to $20-\mathrm{G}$ needles used in the study; results showed that larger tissue samples were acquired using the 20-G FNB needle compared with the 19-G FNA needle $(2.57 \pm 1.85$ vs. $1.36 \pm 1.78 ; p=0.118)$. Therefore, the better tissue acquisition ability of the FNB needle was not related to the needle size. Second, FNA procedures were performed earlier in our cohort than the FNB procedures. However, even if we summed up the total number of procedures performed by each endoscopist (44 cases for Dr. Lin and 16 cases for Dr. Chang), they were still unable to achieve skill maturation (i.e., performed more than 50 cases) according to the current consensus. Third, the FNA group showed a decreasing malignant diagnostic sensitivity (from $71.4 \%$ to $57.1 \%$ to $33.3 \%)$. To clarify this condition, we analyzed the reasons why the results of procedures performed in each group were considered undiagnostic (Table 4). Five cases in the FNA group had atypical cells or glands without evidence of stromal invasion. All of them appeared in cases 11 to 30 in the FNA group and contributed to the decreased diagnostic sensitivity. Therefore, due to the inferior tissue acquisition ability of FNA needles, more needle passes are required to obtain enough tissue samples in order to establish a diagnosis. The slightly decreased number of needle passes observed in the FNA group (Fig. 3) may also contribute to the decreasing diagnostic sensitivity. Thus, more needle passes may be required to achieve adequate diagnostic sensitivity with FNA needles in hospitals without ROSE, especially when the procedure is performed by an inexperienced operator. Fourth, our study included a relatively small number of patients with malignant diseases; if any lesions were missed during the EUS TA procedure, the diagnostic sensitivity will be greatly affected. Fifth, only two target lesions less than $1 \mathrm{~cm}$ in size were detected, and the learning time may be longer in EUS TA of small targets.

In conclusion, the FNB needle has superior tissue acquisition ability compared with FNA needles. It does not only improve the EUS TA efficiency of experienced endosonographers, but also accelerates the skill maturation of trainee endosonographers.

Conflicts of Interest

The authors have no potential conflicts of interest.

Funding

None.
Acknowledgments

We would like to thank Dr. Michelle Lee, from the Department of Emergency of National Cheng Kung University Hospital, for providing English editing assistance.

\section{Author Contributions}

Conceptualization: Meng-Ying Lin

Data curation: MYL, Cheng-Lin Wu

Formal analysis: MYL

Investigation: MYL, Wei-Lun Chang

Methodology: WLC

Project administration: MYL, WLC

Resources: Bor-Shyang Sheu

Software: MYL

Supervision: BSS, WLC

Validation: Mitsuhiro Kida

Visualization: WLC

Writing-original draft: MYL, CLW

Writing-review\&editing: WLC

ORCID
Meng-Ying Lin

Cheng-Lin Wu:

Mitsuhiro Kida:

Wei-Lun Chang:

Bor-Shyang Sheu: https://orcid.org/0000-0003-3896-5695 https://orcid.org/0000-0002-1331-2092 https://orcid.org/0000-0002-5794-1130 https://orcid.org/0000-0002-0238-527X https://orcid.org/0000-0002-1500-6929

\section{REFERENCES}

1. Vilmann P, Jacobsen GK, Henriksen FW, Hancke S. Endoscopic ultrasonography with guided fine needle aspiration biopsy in pancreatic disease. Gastrointest Endosc 1992;38:172-173.

2. Mohammad Alizadeh AH, Shahrokh S, Hadizadeh M, Padashi M, Zali MR. Diagnostic potency of EUS-guided FNA for the evaluation of pancreatic mass lesions. Endosc Ultrasound 2016;5:30-34.

3. Horwhat JD, Paulson EK, McGrath K, et al. A randomized comparison of EUS-guided FNA versus CT or US-guided FNA for the evaluation of pancreatic mass lesions. Gastrointest Endosc 2006;63:966-975.

4. Okasha HH, Naga MI, Esmat S, et al. Endoscopic ultrasound-guided fine needle aspiration versus percutaneous ultrasound-guided fine needle aspiration in diagnosis of focal pancreatic masses. Endosc Ultrasound 2013;2:190-193.

5. Erickson RA, Sayage-Rabie L, Beissner RS. Factors predicting the number of EUS-guided fine-needle passes for diagnosis of pancreatic malignancies. Gastrointest Endosc 2000;51:184-190.

6. Erickson RA, Garza AA. Impact of endoscopic ultrasound on the management and outcome of pancreatic carcinoma. Am J Gastroenterol 2000;95:2248-2254.

7. Itoi T, Tsuchiya T, Itokawa F, et al. Histological diagnosis by EUS-guided fine-needle aspiration biopsy in pancreatic solid masses without on-site cytopathologist: a single-center experience. Dig Endosc 2011;23 Suppl 1:34-38.

8. Eisen GM, Dominitz JA, Faigel DO, et al. Guidelines for credentialing and granting privileges for endoscopic ultrasound. Gastrointest Endosc 2001;54:811-814

9. Wani S, Coté GA, Keswani R, et al. Learning curves for EUS by using cumulative sum analysis: implications for American Society for Gastrointestinal Endoscopy recommendations for training. Gastrointest Endosc 2013;77:558-565.

10. Polkowski M, Larghi A, Weynand B, et al. Learning, techniques, and complications of endoscopic ultrasound (EUS)-guided sampling in gas- 
troenterology: European Society of Gastrointestinal Endoscopy (ESGE) Technical Guideline. Endoscopy 2012;44:190-206.

11. Mertz H, Gautam S. The learning curve for EUS-guided FNA of pancreatic cancer. Gastrointest Endosc 2004;59:33-37.

12. Cho IR, Chung MJ, Bang S, et al. Gemcitabine based neoadjuvant chemoradiotherapy therapy in patients with borderline resectable pancreatic cancer. Pancreatology 2013;13:539-543.

13. Petrelli F, Coinu A, Borgonovo K, et al. FOLFIRINOX-based neoadjuvant therapy in borderline resectable or unresectable pancreatic cancer: a meta-analytical review of published studies. Pancreas 2015;44:515-521.

14. Naveed M, Siddiqui AA, Kowalski TE, et al. A Multicenter comparative trial of a novel EUS-guided core biopsy needle (SharkCoreTM) with the 22-gauge needle in patients with solid pancreatic mass lesions. Endosc Ultrasound 2018;7:34-40.

15. Haseeb A, Taylor LJ, Adler DG. Comparing endoscopic ultrasound-guided core biopsies of solid pancreatic and extrapancreatic lesions: a large single-operator experience with a new fine-needle biopsy needle. Ann Gastroenterol 2018;31:742-746.

16. Witt BL, Factor RE, Chadwick BE, Caron J, Siddiqui AA, Adler DG. Evaluation of the SharkCore ${ }^{\oplus}$ needle for EUS-guided core biopsy of pancreatic neuroendocrine tumors. Endosc Ultrasound 2018;7:323-328.

17. Meenan J, Harris K, Oppong K, et al. Service provision and training for endoscopic ultrasound in the UK. Frontline Gastroenterol 2011;2:188194.

18. Cazacu IM, Luzuriaga Chavez AA, Saftoiu A, Vilmann P, Bhutani MS. A quarter century of EUS-FNA: progress, milestones, and future directions. Endosc Ultrasound 2018;7:141-160.

19. Iwashita T, Yasuda I, Mukai T, et al. Macroscopic on-site quality evaluation of biopsy specimens to improve the diagnostic accuracy during EUS-guided FNA using a 19-gauge needle for solid lesions: a single-center prospective pilot study (MOSE study). Gastrointest Endosc 2015;81:177-185.

20. Ishiwatari H, Sato J, Fujie S, et al. Gross visual inspection by endosonographers during endoscopic ultrasound-guided fine needle aspiration. Pancreatology 2019;19:191-195.

21. Leung Ki E-L, Lemaistre A-I, Fumex F, et al. Macroscopic onsite evaluation using endoscopic ultrasound fine needle biopsy as an alternative to rapid onsite evaluation. Endosc Int Open 2019;7:E189-E194.

22. Oh D, Seo DW, Hong SM, et al. The impact of macroscopic on-site evaluation using filter paper in EUS-guided fine-needle biopsy. Endosc Ultrasound 2019;8:342-347.

23. Micames C, Jowell PS, White R, et al. Lower frequency of peritoneal carcinomatosis in patients with pancreatic cancer diagnosed by EUS-guid- ed FNA vs. percutaneous FNA. Gastrointest Endosc 2003;58:690-695.

24. Harewood GC, Wiersema LM, Halling AC, Keeney GL, Salamao DR, Wiersema MJ. Influence of EUS training and pathology interpretation on accuracy of EUS-guided fine needle aspiration of pancreatic masses. Gastrointest Endosc 2002;55:669-673.

25. Wiersema MJ, Vilmann P, Giovannini M, Chang KJ, Wiersema LM. Endosonography-guided fine-needle aspiration biopsy: diagnostic accuracy and complication assessment. Gastroenterology 1997;112:10871095.

26. DiMaio CJ, Kolb JM, Benias PC, et al. Initial experience with a novel EUS-guided core biopsy needle (SharkCore): results of a large North American multicenter study. Endosc Int Open 2016;4:E974-E979.

27. Kandel P, Tranesh G, Nassar A, et al. EUS-guided fine needle biopsy sampling using a novel fork-tip needle: a case-control study. Gastrointest Endosc 2016;84:1034-1039.

28. Bang JY, Hebert-Magee S, Navaneethan U, Hasan MK, Hawes R, Varadarajulu S. EUS-guided fine needle biopsy of pancreatic masses can yield true histology. Gut 2018;67:2081-2084.

29. Mukai S, Itoi T, Yamaguchi H, et al. A retrospective histological comparison of EUS-guided fine-needle biopsy using a novel franseen needle and a conventional end-cut type needle. Endosc Ultrasound 2019;8:5057.

30. Wang J, Zhao S, Chen Y, Jia R, Zhang X. Endoscopic ultrasound guided fine needle aspiration versus endoscopic ultrasound guided fine needle biopsy in sampling pancreatic masses: A meta-analysis. Medicine (Baltimore) 2017;96:e7452.

31. Altonbary A, Hakim H, Bakr D, El-Shamy A, Elkashef W. Comparison of endoscopic ultrasound-guided tissue acquisition using $22 \mathrm{G}$ versus $20 \mathrm{G}$ procore needles in solid lesions: a pilot study. Egypt J Intern Med 2019;31:266-272.

32. Affolter KE, Schmidt RL, Matynia AP, Adler DG, Factor RE. Needle size has only a limited effect on outcomes in EUS-guided fine needle aspiration: a systematic review and meta-analysis. Dig Dis Sci 2013;58:10261034.

33. Ramesh J, Bang JY, Hebert-Magee S, et al. Randomized Trial Comparing the Flexible 19G and 25G Needles for Endoscopic Ultrasound-Guided Fine Needle Aspiration of Solid Pancreatic Mass Lesions. Pancreas 2015;44:128-133.

34. Facciorusso A, Wani S, Triantafyllou K, et al. Comparative accuracy of needle sizes and designs for EUS tissue sampling of solid pancreatic masses: a network meta-analysis. Gastrointest Endosc 2019;90:893-903. e7. 